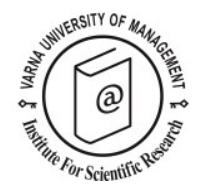

\title{
Perceived impact of tourism by the resident population in Torrevieja: national versus non-national residents
}

\author{
Fernando A. López Hernández ${ }^{1 *}$ and Sara de la Santísima Trinidad Mercader ${ }^{2}$
}

Received: 14/11/2014 Accepted: 18/12/2014

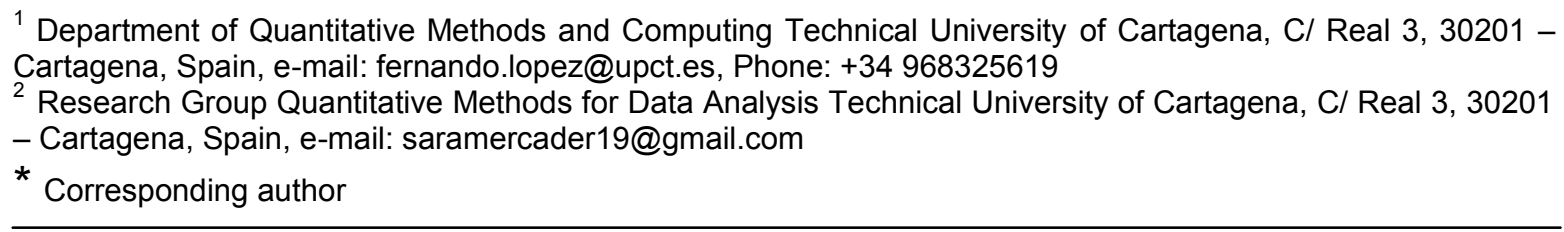

\section{Abstract}

The perception of the impact of tourism on the resident population is the key to the tourist industry. The tourist development of the Mediterranean coast has led to a population explosion where the largest figures are of non-national origin, which have become the majority, ahead of the Spanish population. Nationality in the perception of the host population has been overlooked, but this is an important factor in Torrevieja (Spain), where more than $50 \%$ of the host population is non-national. Our finding confirms that these two host groups, national and non-national, have different perceptions of the impact of tourism in the area.

(C) 2015 Varna University of Management. All rights reserved

Keywords: tourism perception, cross-national, non-national residents, tourism impact.

Citation: Lopez, F., S. Mercader (2015) Perceived impact of tourism by the resident population in Torrevieja: national versus non-national residents. European Journal of Tourism Research 10, pp. $120-126$

\section{Introduction}

The attitude of residents to tourism has been a topic that has attracted considerable interest in the field of tourism research (Liu and Var, 1986; Allen et al., 1988; Ap, 1992; Casado-Díaz, 1999; Besculides et al., 2002; Ritchie and Inkari, 2006; Andereck et al., 2007; Cecil et al., 2010; Long and Kayat, 2011; Xie et al., 2012; Michalkó et al., 2013; Wang, 2013). All these studies on this topic suggest that the attitude of residents is influenced by the manner in which the host community perceive the impact of tourism, including economic, socio-cultural and environmental aspects. Most of the studies(Allen et al., 1988; Besculides et al., 2002; Ritchie and Inkari, 2006; Andereck et al. 2007; Cecil et al 2010; Long and Kayat, 2011; Xie et al., 2012; Wang, 2013), the host community is a heterogeneous group of individuals who have different reactions to the same impacts. To know how the different groups of individuals perceive these impacts, studies have considered different factors (social, demographic and economic) that could initially affect perception. 
Although there is a huge literature that has considered the ethnicity factor (Liu and Var, 1986; Um and Crompton, 1987; Besculides et al., 2002; Long and Kayat, 2011; Wang, 2013) the nationality of host residents has been overlooked. This is an important factor in some municipalities on the Spanish Mediterranean coast where there is a higher percentage of non-national than of national residents. This non-national population, mostly from Central and Northern Europe, is settled and has been living in Spain for some time.

Although there may be doubts about the group to which these people belong, hosts or tourists, there are several reasons for classifying them as hosts. Firstly, due to the historical process of this population's settlement in the municipality, the majority have long times of residence. A long time of residence is expected to generate some level of attachment to the region ( $\mathrm{Gu}$ and Ryan, 2010), enabling their classification as hosts of seasonal tourism. Secondly, most of them have a second residence in the municipality, usually owned, so they are registered in the municipal census and have official resident status. This gives them access to many free municipal and regional services, especially healthcare. Furthermore, these nonnational residents are entitled to vote in municipal elections and local corporations therefore treat them as a host population, whose opinions are important enough to encourage positive attitudes.

The objective of this note is to present a crossnational analysis about the perceptions of residents regarding the impacts of tourism. Specifically we evaluate whether the nationality of host residents (national versus non-national) is a relevant factor in the perception of the impact of tourism.

\section{Literature review}

Studies of the perception of the impact of tourism have proliferated over recent decades (Deery et al., 2012 and Sharpley, 2014 describe the main contributions made on this topic). Mostly, these studies take several factors into account in order to include the heterogeneous nature of the host community (Liu and Var, 1986; Long and Katat, 2011; Cecil, 2008; Long and Kayat, 2011; Wang,
2013). Indeed, the theory recognizes the heterogeneous nature of a host community (Ap, 1992), where different groups of individuals may hold different attitudes to tourism depending on their perceptions. Several studies (Liu and Var, 1986; Andereck et al., 2007; Cecil, 2008; Long and Kayat, 2011; Wang, 2013) also took into consideration the role of socio-demographic aspects in the perception of hosts (such as age, language, sex, ethnicity, marital status, educational levels, etc). However, the results of these studies have not been entirely consistent with respect to the ethnicity factor; some of the evidence (Um and Crompton, 1987; Besculides et al., 2002; Long and Kayat, 2011) confirms the influence of ethnicity factors on residents' perceptions whereas others have not made such connections (Liu and Var, 1986; Cecil, 2008; Wang, 2013).

Although there is considerable literature about the perception of the impact of tourism by residents, the nationality of the host population is overlooked and only a few papers explore this topic. In a study of northern Wales, Sheldon and Var (1984) discovered evidence suggesting that residents' perceptions toward tourism development are culturally bound, finding that natives and Welsh speakers were more sensitive to tourism's social and cultural impacts than were non-natives and non-Welsh speakers. Um and Crompton (1987) found German ethnicity was a factor in attitudes toward tourism development, discovering that the more attached a resident was to the community regarding birthplace, heritage, and length of residence, the less positively he or she perceived impacts, with the exception of perceived adverse impacts on environmental quality.

Most recently, Besculides et al. (2002) examined the perception of cultural tourism by Hispanic and non-Hispanic residents. The results of this paper showed differences between the two groups. Andereck et al. (2007) present a cross-cultural analysis of tourism and quality of life perceptions with the objective of exploring the differences between Hispanic and Anglo residents. The results showed differences and similarities between the two groups with respect to the perceived 
importance level, satisfaction level and effects of tourism on quality of life. Finally, Xie et al. (2012) examined whether tourism impacts affect the overall satisfaction of native-born and non-native-born residents in Huangshan, a famous tourist destination in China. The results of this study showed that the impactsatisfaction relationship varied between different groups in the community (e.g., natives versus non-natives).

\section{Methodology}

Study site and resident status

In order to shed light on this issue, a study was conducted in the Spanish municipality of Torrevieja, a town in south-eastern Spain on the Mediterranean coast, where the settlement process is strong and there is a high percentage of non-national population who have been in residence for more than 10 years (Casado-Díaz, 1999). Among all municipalities with more than 20000 inhabitants, it has the highest percentage of non-national residents in Spain. In the last three five-year periods, this municipality underwent a strong demographic explosion resulting from growth of tourism, largely residential and primarily from European countries. In 2011, there were 102136 registered inhabitants, more than 52\% (53570) of whom were non-national.
In this research we only consider inhabitants who have resident status. To obtain such status everyone who lives in Spain, national or non-national, must register in the Municipal Census and prove that they are living in the area covered by the local council (rental agreement, house ownership, etc). Several rights and responsibilities apply if one has resident status: being able to vote and be elected in local and regional elections and the use of municipal and regional public services such as healthcare and education (schools, libraries, access to courses), etc.

\section{Procedure}

To ensure a representative sample, the municipal population was stratified based on census data. Information was collected from 164 residents, proportionally stratified by age, gender and major nationality (continent), from March to August 2012, through personal interviews. The sample size was based on the fact that $70 \%$ of the registered population $(p=0.7)$ had been in residence for more than 10 years; it was calculated in order to obtain a similar percentage with a $95 \%$ confidence level and $\pm 7 \%$ accuracy. The items of this study were derived from a review of existing literature about perceived impact of tourism and surveys in a similar paper. The questionnaire contained

Table 1.Socio-demographic characteristics of the sample

\begin{tabular}{|c|c|c|c|}
\hline & National $(\mathrm{N})$ & Non-national $^{\mathrm{a}}(\mathrm{N})$ & Total $(\mathrm{N})$ \\
\hline \multicolumn{4}{|l|}{ Gender } \\
\hline Men & $52.6 \%(41)$ & $46.5 \%(40)$ & $49.4 \%(81)$ \\
\hline Women & $47.4 \%(37)$ & $53.5 \%(46)$ & $50.6 \%(83)$ \\
\hline \multicolumn{4}{|l|}{ Age } \\
\hline$<45$ years & $34.6 \%(27)$ & $44.2 \%(38)$ & $39.6 \%(65)$ \\
\hline$\geq 45$ years & $65.4 \%(51)$ & $55.8 \%(48)$ & $60.4 \%(99)$ \\
\hline \multicolumn{4}{|l|}{ Time of residence } \\
\hline$\geq 10$ years & $78.2 \%(61)$ & $43.0 \%(37)$ & $59.8 \%(98)$ \\
\hline$<10$ years & $21.8 \%(17)$ & $57.0 \%(49)$ & $40.2 \%(66)$ \\
\hline \multicolumn{4}{|l|}{ Area of residence } \\
\hline Periphery & $8.1 \%(7)$ & $42.3 \%(33)$ & $24.4 \%(40)$ \\
\hline Core & $91.9 \%(79)$ & $57.7 \%(45)$ & $75.6 \%(124)$ \\
\hline \multicolumn{4}{|l|}{ Educational level } \\
\hline Elementary Education & $44.2 \%(38)$ & $26.9 \%(21)$ & $36.0 \%(59)$ \\
\hline High school or University & $55.8 \%(48)$ & $73.1 \%(57)$ & $64.0 \%(105)$ \\
\hline
\end{tabular}

(Absolute values in brackets)

${ }^{a}$ Nationalities: Argentina, 1; Bangladesh, 1; Belgium, 6; Bulgaria, 1; Chile, 1; Colombia, 4; Cuba, 2; Ecuador, 1; France,

7; Germany, 15; Hungary, 3; Ireland, 3; Italy, 4; Lithuania, 1; Morocco, 3; Netherlands, 1; Romania, 1; Russia, 3;

Sweden, 6; Switzerland, 2; Ukraine, 6; United Kingdom, 14 
21 items divided into four sections (Table 2). A 5-point Likert-type scale was used with 1 indicating total disagreement and 5 total agreement. The questionnaire was translated into four languages (English, French, German and Spanish) to account for each interviewee's mother tongue. The non-parametric MannWhitney U-test was used to evaluate mean differences between different subsamples.

\section{Results}

Table 1 shows the socio-demographic characteristics of the sample. The total number of non-national residents was 86 , of 22 different nationalities, with a clear majority living in the outskirts (predominantly resorts). Ninety-eight individuals in the sample had been residents for more than 10 years.

Table 2 show the mean and standard deviation of the 21 items. Most are fairly neutral; 14 of the 21 results presented have a mean between 2.5 and 3.5 , suggesting that there are no strong views, especially in socio-cultural and environmental items. On the other hand, the item with higher mean values $(\bar{x}=4.16)$ and lower standard deviation values $(S=0.79)$ is Global perception (E1) showing strong agreement with a positive perception of the economic impacts of tourism in the respondents.

Table 2 shows the Mann-Whitney U-test to analyse the difference in mean values between national and non-national residents (for all items the Kolmogorov-Smirnov tests are significant indicating that normal distribution assumption required for t-test had been violated). Several differences emerge between both groups. With regards to economic factors, nationality generates significant differences between the average values of the items that assess the positive economic impact of tourism (from E1 to E5), and in all cases the perception of non-nationals is greater than that of national residents. Xie et al. (2012) also found higher means for positive economic items in nonnatives although no significant differences were established. The greatest differences are founded in perception of employment (E3) and investment (E4), as non-national residents believe that tourism creates more job opportunities and attracts more investment to the community, generating economic benefits for local people. Perception of increase in quality of life (E5) is also different in the two groups, with non-national residents presenting a higher value $(\bar{x}=3.89)$ than national $(\bar{x}=3.30)$. These findings are consistent with Liu and Var (1986) who found that variations in respondents' attitudes towards the benefits of tourism occurred when the ethnicity factor was taken into account. On the other hand, differences in items that evaluated negative economic impact (E6-E7) were not significant. Similar results were found in Andereck et al. (2007), with no significant differences in negative impacts between ethnic groups in the quality of life of the respondents.

The second group of items explores the perception of the residents regarding infrastructure improvements. Several papers establish (see Deery et al., 2002) that tourism increased urban development and can be perceived as reducing quality of life. In this study, we found no differences according to nationality in the items that evaluate infrastructures controlled by the local council (IN1-IN13). However, there is a significant difference in the evaluation of healthcare services (IN14, Regional Government responsibility). The mean value of the nonnational host is higher than that of the national host. This difference may be due to the fact that Spain enjoys a national healthcare system that provides free health services to all residents.

When the respondents evaluated the perception of tourism on Socio-Cultural items (SC1-SC3), we found differences between national and non-national residents. Nonnational residents perceive that their lifestyles are more influenced by the arrival of tourists, although no significant differences between the groups were found in social exchange (SC2). National and non-national hosts show the same level of satisfaction in socio-cultural exchange.

Finally, the impact of tourism on environment was explored by the last block of items (EN1EN3). We only found a slightly significant difference in EN3; non-national residents do not perceive tourism as responsible for the degradation of the environment compared to 


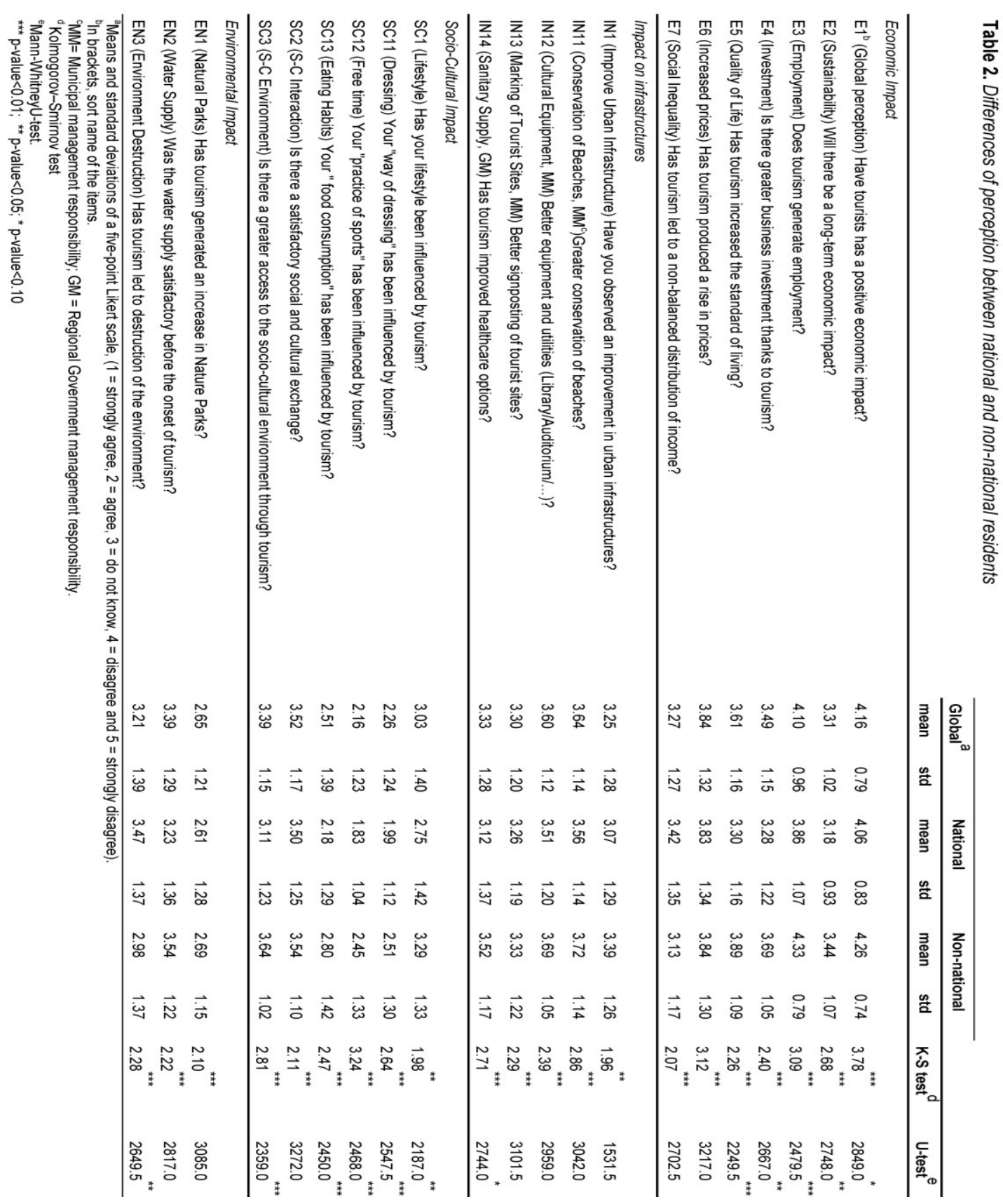

national residents. This difference may be explained as follows. The non-national resident was, in most cases, originally a tourist and therefore does not see him or herself as responsible for the degradation of the environment. In opposite sense Xie et al. (2012) found no significant differences between natives and non-natives.

\section{Conclusions}

This paper explores the perception of residents in a tourist area with a high percentage of nonnational residents, comparing the views of national and non-national hosts. Its main conclusions are that non-national hosts have a more positive perception of the positive economic impact of tourism, while being more 
permeable to socio-cultural influences. Also, the national host group perceives that tourism has a higher negative environmental impact than the non-national host group. On the other hand, both groups have a similar perception of negative economic impacts and improvements to local infrastructures.

Multiple causes could generate these differences in perception between the two groups and the nationality factor was probably only a way to agglutinate all these causes. Cultural background (Andereck et al., 2007), place attachment (Sheldon and Var, 1984), social identity (Haobin, Qiu, Huawenand \& Goh, 2014), emotional solidarity (Woosnam, 2012) or ethnicity (Um and Crompton, 1987) factors could be the source of these differences.

There are no cross-national studies about the perception of the impact of tourism, and only Xie et al. (2012) explore differences between natives and non-natives. Our findings are not similar because Xie et al. (2012) found no significant differences in the survey items, although there were significant differences in impact-satisfaction relationship between the two groups. In order to get more consistent results more research on this topic is necessary.

A limitation of this study might be that it considers the non-national host population as a homogeneous group although in fact it is a mixture of multiple nationalities (with United Kingdom, Germany, Sweden, and France in the lead). Another limitation is the small sample size and, therefore, narrow representation of individuals with diverse nationalities does not enable us to reach universal conclusions with respect to the non-national group. However, the large number of items with different mean values encourages is to study the importance of the nationality factor in the perception of tourist impacts. Research with a larger, broader group of respondents forming a representative sample could provide more relevant behavioural results in future research.

\section{Acknowledgements}

We thank Stanislav Ivanov who provided numerous helpful comments which improved the paper. Fernando López was partially supported by MINECO (Ministerio de Economía y Competitividad) project ECO201236032-C03-01

\section{References}

Allen, L.R., Hafer, H.R., Long, P.T., \& Perdue, R.R. (1993). Rural residents' attitudes toward recreation and tourism development. Journal of Travel Research, 31, 27-33.

Andereck, K.L., Valentine, K.M., Vogt, C.A., \& Knopf, R.C. (2007). A cross-cultural analysis of tourism and quality of life perceptions. Journal of Sustainable Tourism, 15(5), 483-502.

Ap, J. (1992). Residents' perceptions on tourism impacts. Annals of Tourism Research, 19, 665-690.

Besculides, A., Lee, M.E., \& McCormick, P.J. (2002). Residents' perceptions of the cultural benefits of tourism. Annals of tourism research, 29(2), 303-319.

Casado-Díaz, M.A. (1999). Socio-demographic impacts of residential tourism: a case study of Torrevieja, Spain. International Journal of Tourism Research, 1(4), 223-237.

Cecil, A. K., Fu, Y.Y., Wang, S.S., \& Avgoustis, S. (2010). Cultural tourism and quality of life: results of a longitudinal study. European Journal of Tourism Research, 3(1), 54-66.

Cecil, A.K., Fu, Y.Y., Wang, S.S., \& Avgoustis, S. (2008). Exploring resident awareness of cultural tourism and its impact on quality of life. European Journal of Tourism Research, 1(1), 39-52.

Deery, M., Jago, L., \& Fredline, L. (2012). Rethinking social impacts of tourism research: A new research agenda. Tourism Management, 33, 64-73.

Gu, H., \& Ryan, C. (2010). Constructionism and culture in research: understandings of the fourth Buddhist festival, Wutaishan, China. Tourism Management, 31(2), 167178.

Haobin, B., Qiu, H., Huawen, J., \& Goh, C. (2014). Does social identity affect residents' attitude toward tourism development? An evidence from the relaxation of the Individual Visit Scheme. International Journal of Contemporary Hospitality Management, 26(6), 907-929. 
Liu, J. \& Var, T. (1986). Resident attitudes towards tourism impacts in Hawaii. Annals of Tourism Research, 13,193-214.

Long, P. \& Kayat, K. (2011). Residents' Perceptions of Tourism Impact and Their Support for Tourism Development: The Case Study of Cuc Phuong National Park, NinhBinh Province, Vietnam. European Journal of Tourism Research, 4(2), 123146.

Michalkó, G., Bakucz, M., \& Rátz, T. (2013). The relationship between tourism and residents' quality of life: a case study of Harkány, Hungary. European Journal of Tourism Research, 6(2), 154-169.

Ritchie, B.W., and Inkari, M. (2006). Host community attitudes toward tourism and cultural tourism development: the case of the Lewes District, Southern England. International Journal of Tourism Research 8, 27-44.

Sharpley, R. (2014). Host perceptions of tourism: A review of the research. Tourism Management, 42, 37-49.
Sheldon, P.J., \& Var T. (1984).Resident attitudes to tourism in North Wales. Tourism Management, 5, 40-47.

Um, S., \& Crompton J.L. (1987). Measuring resident's attachment levels in a host community. Journal of Travel Research, 26, 27-29.

Wang S. (2013). Predicting effects of demographics and moderating power of engagement on residents' perceptions of tourism development. European Journal of Tourism Research, 6(2), 170-182.

Woosnam, K. M. (2012). Using emotional solidarity to explain residents' attitudes about tourism and tourism development. Journal of Travel Research, 51(3), 315-32.

Xie, H.J., Bao, J., \& Kerstetter, D.L. (2012). Examining the Effects of Tourism Impacts on Satisfaction with Tourism between Native and Non-native Residents. International Journal of Tourism Research. 16(3), 241-249. 